\title{
A picture of global health
}

I $\mathrm{f}$ a picture is worth a thousand words then these images speak volumes about the conditions endured by women and children in India and Indonesia.

These 3 images were among 5 finalists in an annual contest sponsored by the International Women's and Children's Health Network at McMaster University in Hamilton, Ontario. Entries came from students worldwide and depicted aspects of health and community life on nearly every continent.

"These are not the big-story moments that you see in the media," explains Jillian Korolnek, a third-year midwifery student and co-chair of the 2009 network's conference. "These are stories from daily life told in a beautiful way."

The photographs were displayed, then auctioned off at the 2008 conference, with the proceeds, as usual, benefiting a local organization. - Barbara Sibbald, $C M A J$

\section{Notes from the photographers}

Natalie Cartwright, a Masters in Public Health student at Lund University in Lund City, Sweden, acknowledges UNICEF's Knowledge Community on Children in India Internship program. For information on manual scavenging go to: www.ncdhr.org.in /ncdhr/campaigns/manualscavenging

\footnotetext{
荌 Kathleen Margaret Gregory, a medical ठे student at McMaster University in Hamilton, Ontario, extends a special thank you to the \% Peterborough Medical Brigade for including her in this great experience and to the compassionate people of Flores, Indonesia, for welcoming the team into their villages.
}

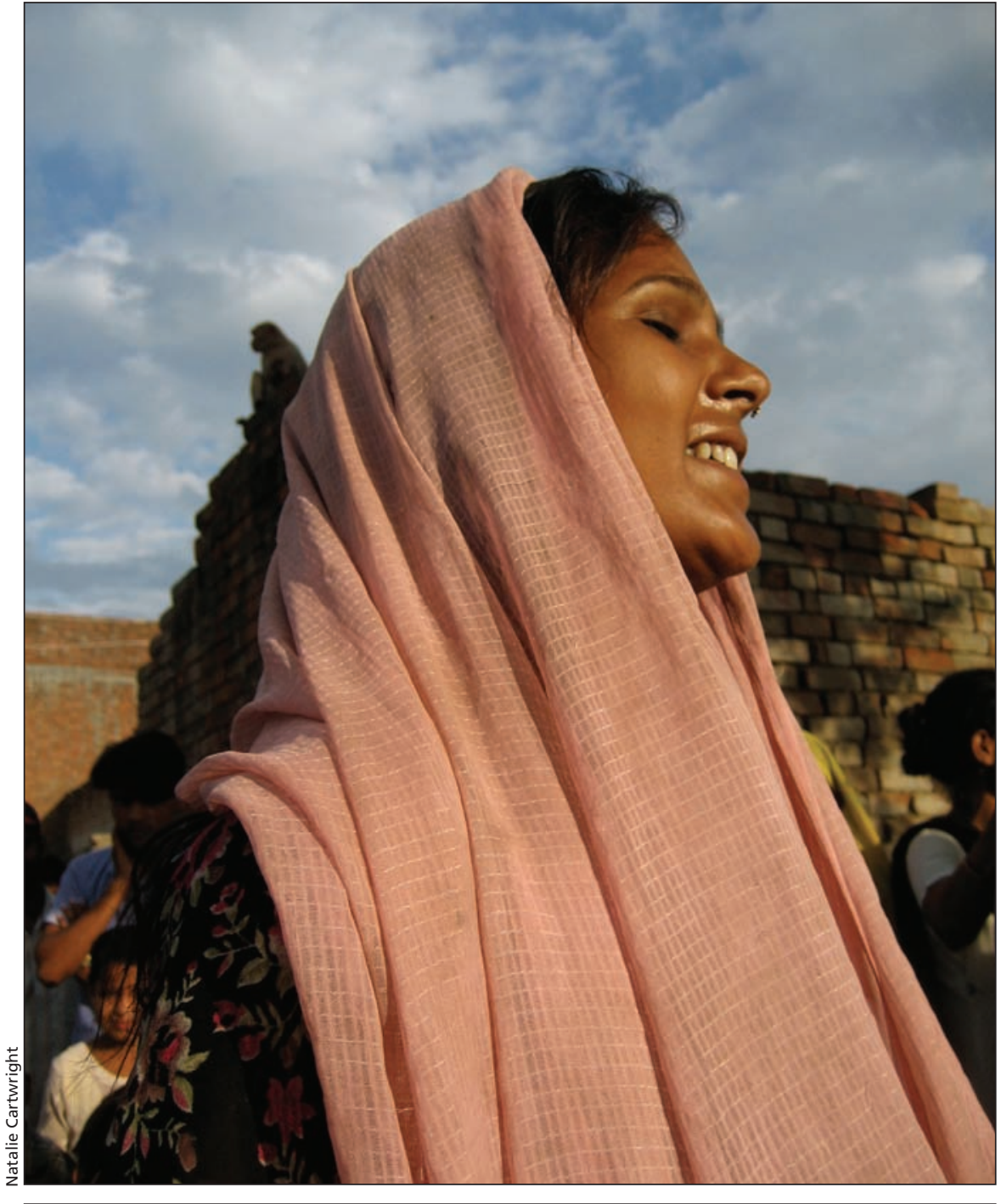

Scavenging Hope: Natalie Cartwright, who took this picture of a manual scavenger in the rural village of Haryana in Moradabad District, Uttar Pradesh, India, writes: "The work of manual scavenging involves the following activities repeated as many as 45 times a day: with wood or tin pieces the scavengers scoop raw fecal matter from the dry latrine (essentially 2 flat stones or bricks placed at the side of the house) and then pour the waste into a loosely woven basket that they carry on their heads. Some feces are sold as manure, but most are disposed of elsewhere. The manual scavengers, $95 \%$ of whom are women, suffer serious health consequences, such as higher incidences of asthma, diarrhea, tuberculosis, liver and intestine problems, and eye infections. Powerful social forces including gender, poverty and caste issues impede successful elimination of manual scavenging. This picture was taken on the last day of a 10-day visit I made as part of a data-collecting team. We sat with the manual scavenger women and they played the drums, sang and danced for us and with us. I think this picture is important because it inspires hope." Manual scavenging in India was banned in 1993, but only about 6 of the 28 states have ratified this law. An estimated 1 million people still work as manual scavangers in India. 
Courage: This photograph was taken by Kathleen Margaret Gregory at what is believed to have been the first medical clinic to come to rural Flores, an island in East Nosa Tenggara Province, Indonesia. The crowd lined up for hours, and this woman, who was one of the last to be seen after waiting at least 7 hours, was always smiling. Her teeth reveal that she uses betel nut, which is used as a stimulant similar to caffeine and is a known carcinogen that also discolours teeth and damages gums.

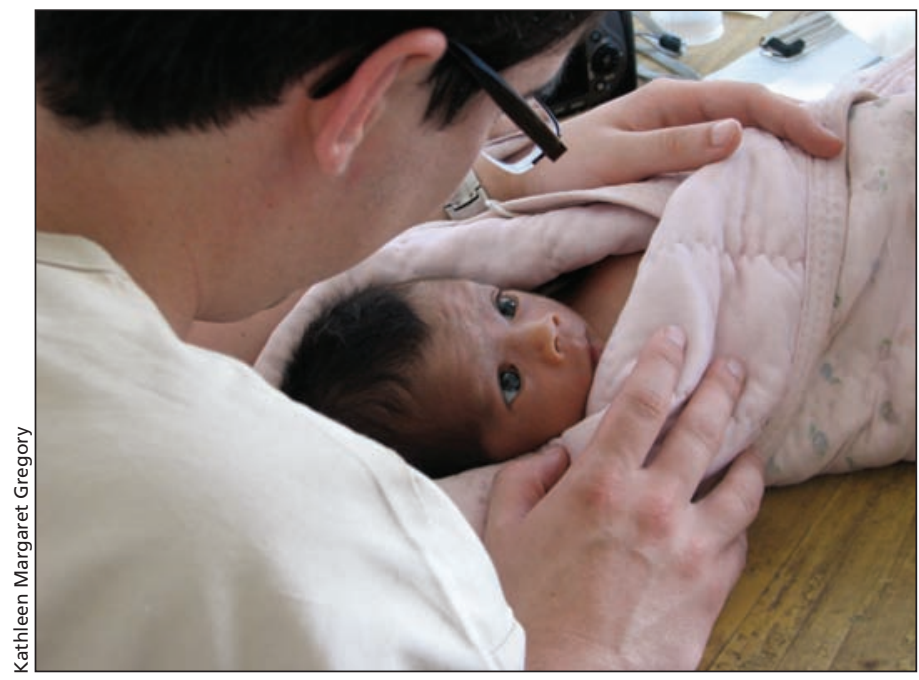

Eyes of strength: At the same free, travelling clinic in another village in Flores, Indonesia, this 3-week-old boy was suffering from failure to thrive. He had pronounced ankyloglossia that appeared to be affecting his ability to breastfeed. After the baby's fraenulum was cut and he had practised feeding from a cleft-palate bottle (his mother pumped breast milk) the child finally became more alert. He opened his eyes; his mother explained that they had not been open in 2 weeks. This photograph was taken after he had had a good feeding. After practising the latching process on the bottle, the baby went on to latch well on his mother. Also seen in this photograph is a member of the team, Dr. Matthew Miller from the University of Ottawa, Ontario. 